\title{
Adilcevaz Bölgesinde Rüzgâr Enerji Potansiyelinin İncelenmesi
}

\author{
Soner ÇELİKDEMIR ${ }^{1 *}$, Mahmut Temel ÖZDEMİR ${ }^{2}$ \\ ${ }^{1}$ Bitlis Eren Üniversitesi, Adilcevaz MYO, Bitlis

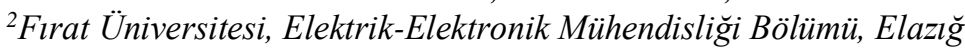 \\ (ORCID: 0000-0002-1419-3398) (ORCID: 0000-0002-5795-2550)
}

\begin{abstract}
$\ddot{\mathbf{O} z}$
Günümüz dünyasında artan enerji ihtiyaçlarını karşılayabilmek ve enerjide dışa olan bağımlılığı azaltabilmek büyük bir önem arz etmektedir. Enerji kaynakları arasında ise yenilenebilir enerji kaynakları büyük bir öneme sahiptir. Rüzgâr enerji potansiyeli iki parametreli Weibull Dağılım Fonksiyonunun Grafik Yöntemi kullanılarak $10 \mathrm{~m}$ ve $100 \mathrm{~m}$ yükseklik değerleri için hesaplanmıştır. Çalışmada ayrıca etkin rüzgâr yönü verilerek elde edilen değerlerin hata oranları, rüzgâr enerji güç yoğunlukları ve kapasite faktör değerleri hesaplanmıştır. Hesaplanan enerji potansiyelleri dikkate alındığı zaman bölgenin rüzgâr enerji santralleri proje yatırımlarına uygun olduğu görülmüsşür. Böylece, genel olarak Adilcevaz bölgesinin rüzgâr enerji potansiyelinin belirlenmesi amaciyla bir ön çalışma yapılmıştır.
\end{abstract}

Anahtar kelimeler: Rüzgâr Enerjisi, Weibull Dağılımı, Enerji Potansiyeli.

\section{Investigation of Wind Energy Potential in Adilcevaz Region}

\begin{abstract}
In today's world, it is of great importance to meet increasing energy needs and to reduce the dependence on foreign energy. Among the energy sources, renewable energy sources are of great importance. The wind energy potential was calculated for the $10 \mathrm{~m}$ and $100 \mathrm{~m}$ elevation values using the two-parameter Weibull Distribution Function Graphical Method. In the study, error rates, wind energy power densities and capacity factor values of the values obtained by giving effective wind direction were calculated. When the calculated energy potentials are taken into consideration, it is seen that the wind power plants in the region are suitable for the project investments. Thus, a preliminary study was conducted to determine the wind energy potential of the Adilcevaz region in general.
\end{abstract}

Keywords: Wind Energy, Weibull Distribution, Energy Potential.

\section{Giriş}

Dünya nüfusunun artış gösteren eğimi ile birlikte artan enerji ihtiyaçlarını karşılamak için enerjiye olan talep de artmaktadır. Buna karşın azalan enerji kaynakları, artan maliyetleri ve çevreye vermiş oldukları zararlar dikkate alındığında yeni enerji kaynak arayışları ve mevcut yenilenebilir enerji kaynaklarına olan talep de artış göstermektedir. Teknolojik gelişmeler ile birim üretim maliyetlerinin azalması ve enerji kalitesinin artması yenilenebilir enerji kaynakların önemini ön plana çıkarmaktadır. Yenilenebilir enerji kaynakları içerisinde rüzgâr enerjisinin çevre dostu bir kaynak olmasından dolayı daha verimli faydalanma söz konusudur.

Bu çalışmada, Adilcevaz bölgesinin rüzgâr enerji potansiyeli incelenmiştir. Çalışmada, bölgenin 2018 yılına ait $10 \mathrm{~m}$ yükseklikte ölçülen saatlik rüzgâr hız verileri kullanılmıştır. $100 \mathrm{~m}$ yükseklik için rüzgâr hız değerleri Hellmann Bağıntısı kullanılarak bulunmuştur. Çalışmada ayrıca Adilcevaz bölgesine ait rüzgâr enerji potansiyelinin belirlenmesi amaçlanmıştır. Bunun için Devlet Meteoroloji İl Müdürlügü̆'nden alınan Adilcevaz bölgesi için 2018 yılına ait 10 m yükseklikte ölçülen saatlik rüzgâr

*Sorumlu yazar: celikdemirsoner@gmail.com

Geliş Tarihi: 13.02.2019, Kabul Tarihi: 31.07.2019 
hız değerleri kullanılmıştır. Bölgenin rüzgâr enerji potansiyeli incelenirken, gerçek rüzgâr hız verileri kullanılarak farklı yükseklikler için hesaplanan rüzgâr hız değerleri ve Weibull Dağılımı kullanılmıştır. Kaplan [1] yaptı̆̆ çalışmada Osmaniye Bölgesi için 2013 yılına ait saatlik olarak ölçülen rüzgâr hız verileri kullanılarak rüzgâr enerjisi potansiyelini istatiksel olarak analiz etmiştir. Ayrıca mevcut rüzgâr hız verilerinin Weibull ve Rayleigh Dağılım fonksiyonlarına uyumunu incelemiştir. Gülersoy ve Çetin [2] yaptıkları çalışmada Menemen Bölgesinde 2008-2009 yıllarında saatlik olarak ölçülen rüzgâr hız değerlerini kullanarak bölgenin rüzgâr enerji potansiyelini istatiksel olarak incelemişlerdir. Ölçülen rüzgâr hız verileri kullanarak, rüzgâr hızlarının esme saatlerinin Weibull ve Rayleigh dağılım fonksiyonuna uyumunu araştırmışlardır. Yıldırım ve arkadaşları [3] yaptıkları çalışmada Niğde iline ait 10 m yükseklikte ölçülen saatlik ortalama rüzgâr hız değerleri kullanılarak bölgenin rüzgâr enerji potansiyeli istatiksel olarak incelemişlerdir. Kurban ve arkadaşları [4] yaptıkları çalışmada Anadolu Üniversitesi İki Eylül Kampüsü’ndeki 2005 yılına ait 15 saniye aralıklarla ölçülen rüzgâr hız verilerine dayanarak rüzgâr gücünün değişimini Weibull Dağılımı ile incelemiş̧lerdir. Diğer çalışmalarda [5-14] genel olarak yıllık ortalama rüzgâr hızı ve rüzgâr gücü yoğunlukları farklı bölgelerde uygun türbin modeli için, enerji üretimi, kapasite faktörü ve maliyet analizleri yapılarak karşılaştırılmıştır.

\section{Dünya ve Türkiye'deki Rüzgâr Enerji Potansiyeli}

Yenilenebilir enerji kaynaklarından biri olan rüzgâr enerji santralleri (RES) Dünya'daki elektrik enerji gereksiniminin yaklaşık olarak \% 7,7'sini karşılamaktadır. Bu durum hali hazırda değerlendirilmemiş olan rüzgâr enerji potansiyellerinin önemini artırmaktadır. Rüzgâr türbinleri bir sistem yada bir bölgenin enerji ihtiyacını karşılayacağı gibi ürettiği enerjiyi enterkonnekte şebeke üzerinden sisteme verebilmektedir.

Ülkemizin kurulu güç değeri 2018 yılı Aralık ayı sonu itibari ile 83.184 MW'a ulaşmıştır. 2018 yılı Aralık ayı sonunda kurulu gücümüzün enerji kaynaklarına göre oranları Tablo 1 ve Şekil 1'de gösterilmiş olup; \% 34,0'1 hidrolik enerji, \% 30,95'i doğal gaz, \% 23,03'ü kömür, \% 8,34'ü rüzgâr, \% 0,1 'i güneş, \% 1,54'ü jeotermal ve \% 20,4'i ise diğer enerji kaynakları şeklindedir. Türkiye'nin rüzgâr enerji potansiyeli $48.000 \mathrm{MW}$ olarak hesaplanmıştır. Bu potansiyel değere karşıllık gelen toplam alan Türkiye yüz ölçümünün \%1,30'una denk gelmektedir. Ayrıca 2017 yıl sonu itibariyle Türkiye'de rüzgâr enerjisinden 17,9 milyar kWh elektrik enerjisi üretilmiştir. 2018 Haziran ay sonu itibariyle işletmede olan rüzgâr enerji santrallerinin toplam kurulu gücü 6,671 MW'tır. Türkiye'nin karasal alanlarda brüt rüzgâr enerji potansiyeli 400 milyar $\mathrm{kWh} / \mathrm{yl}$, teknik rüzgâr enerji potansiyeli 120 milyar $\mathrm{kWh} / \mathrm{y}$ ll ve ekonomik olarak rüzgâr enerji potansiyeli ise 50 milyar $\mathrm{kWh} / \mathrm{y} 1 \mathrm{l}$ olarak hesaplanmaktadır.

Tablo 1. Elektrik üretim tesislerinin toplam kurulu güç ve oranları [15]

\begin{tabular}{|l|r|c|}
\hline \multirow{2}{*}{\multicolumn{1}{|c|}{ Kaynak Türü }} & \multicolumn{2}{|c|}{$\mathbf{2 0 1 8}$} \\
\cline { 2 - 3 } & $\begin{array}{c}\text { Kurulu Güç̧ } \\
\text { (Mw) }\end{array}$ & Oran (\%) \\
\hline Doğal Gaz & $25.741,66$ & 30,95 \\
\hline Barajlı Hidrolik & $20.536,05$ & 24,69 \\
\hline Linyit & $9.597,12$ & 11,54 \\
\hline İthal Kömür & $8.938,85$ & 10,75 \\
\hline Akarsu & $7.747,65$ & 9,31 \\
\hline Rüzgâr & $6.939,77$ & 8,34 \\
\hline Jeotermal & $1.282,52$ & 1,54 \\
\hline Fuel Oil & 709,21 & 0,85 \\
\hline Taş Kömürü & 616,15 & 0,74 \\
\hline Biyokütle & 581,17 & 0,70 \\
\hline Asfaltit & 405,00 & 0,49 \\
\hline Güneș & 81,66 & 0,10 \\
\hline Nafta & 4,74 & 0,01 \\
\hline Lng & 1,95 & 0,00 \\
\hline Motorin & 1,04 & 0,00 \\
\hline Toplam & $83.184,53$ & 100,00 \\
\hline
\end{tabular}




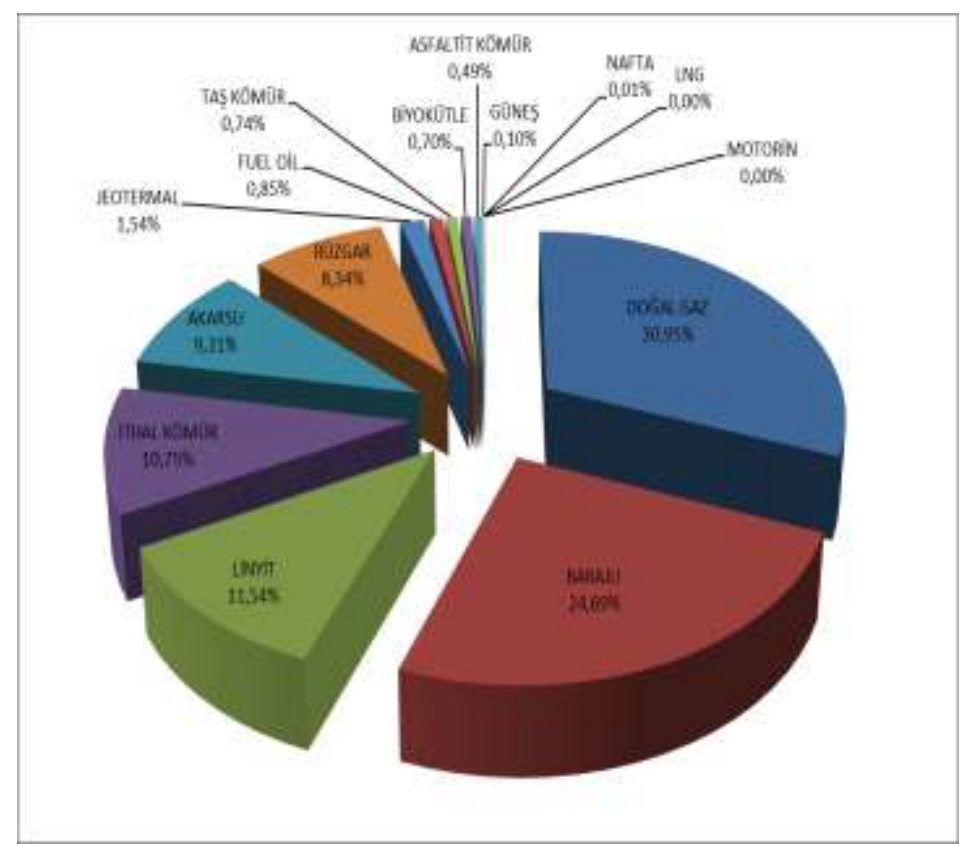

Şekil 1. Elektrik üretim tesislerin yüzdelik oranları [15]

\section{3. İstatiksel Analiz}

\subsection{Rüzgâr Hız Güç Denklemi}

Rüzgâr hızları, yer küreden yükseldikçe değişmektedir. Yeryüzüne yaklaştıkça da sürtünme kuvvetinin etkisiyle rüzgâr hızı düşmektedir. Herhangi bir yükseklikte ölçülen rüzgâr hızı ile başka bir yükseklikteki rüzgâr hızı tahmin edilebilmektedir. Bunun için en yaygın kullanılan bağıntı Hellmann Denklemidir. Rüzgâr hız ölçümleri Dünya Meteoroloji Teşkilatı'nın belirlemiş olduğu 10 m yükseklikte yapılmaktadır. Rüzgâr türbinleri ise daha fazla yüksekliğe sahip olduğundan Hellmann Denklemi kullanılarak rüzgâr türbin yüksekliğindeki rüzgâr hızı hesaplanabilmektedir. Hellmann Denklemi;

$\frac{V}{V_{0}}=\left(\frac{H}{H_{0}}\right)^{\alpha}$

Burada; $H_{0}$ referans yükseklik, $V_{0}$ ise referans yükseklikteki rüzgâr hızı, $H$ rüzgâr hızının hesaplanmak istendiği yükseklik, $V$ ise $H$ yüksekliğindeki rüzgâr hızı, $\alpha$ ise sürtünme katsayısıdır. Sürtünme katsayısı, rüzgâra maruz kalan bölgenin topolojisine bağlı bir katsayı değeridir. Sürtünme katsayı değerleri farklı bölgeler için Tablo 2'de verilmiştir.

Tablo 2. Farklı bölgeler için ' $\alpha$ ' katsayı değeri

\begin{tabular}{|l|c|}
\hline \multicolumn{1}{|c|}{ Bölge Açıklaması } & ' $\boldsymbol{\alpha}$ ' Katsayı Değeri \\
\hline Pürüzsüz, sert zemin, göl, okyanus yüzeyi & 0,10 \\
\hline İşlenmemiş toprak üzerinde kısa çim & 0,14 \\
\hline Ayak seviyesinde çim & 0,16 \\
\hline Maki, fundalık ağaçlarla kaplı zemin & 0,20 \\
\hline Birçok ağaç ve aralıklı bina & $0,22-0,24$ \\
\hline Ağaçlık ve küçük kasaba & $0,28-0,30$ \\
\hline Yüksek binalar, şehir merkezleri & 0,40 \\
\hline
\end{tabular}

\subsection{Weibull Dağılımı}

Rüzgâr hız değerlerinin hakim yön ve şiddetlerinin bulunması için farklı dağılım yöntemleri bulunmaktadır. Bu yöntemler arasında en çok tercih edilen yöntem Weibull dağılımıdır. Rüzgâr hızının 
belli bir periyottaki değişimi ve rüzgâr dağılımı, hem rüzgâr enerji santral yatırım değerlendirmelerinde hem de rüzgâr endüstrisinde büyük bir önem arz etmektedir. Rüzgâr türbin üreticileri, türbin teknolojisindeki gelişmeleri ve maliyetleri en aza indirmede rüzgâr dağılımı ve değişimi ile ilgili bilgilere ihtiyaç duyarlar. Bir bölge için rüzgâr dağılımı ölçülerek ya da ölçümlere dayalı farklı nokta ve yüksekliklerde Weibull Dağılımı ile hesaplanır. Weibull Dağılımı eğrisi iki parametreye sahip olup simetrik değil çarpıktır. Bu dağılımı oluşturan her bir hız frekansı, ortalama hızın bulunmasını da sağlar. Weibull Dağılımı;

$p(v)=\left(\frac{k}{c}\right)\left(\frac{v}{c}\right)^{k-1} \exp \left[-\left(\frac{v}{c}\right)^{k}\right]$
$p(v)=P^{\prime}(v)$

Burada; $P^{\prime}(v)$ birikmiş olasılık dağılım fonksiyonu, $p(v)$ rüzgâr hızının olasılık yoğunluğunu, $k$ şekil parametresini, $c$ ise ölçek parametresini ifade eder. $k$ şekil parametresini genellikle 1,5 ile 3 arasında olması beklenmektedir. Weibull Dağılımı farklı metotlarla çizilebilmektedir. En yaygın olarak kullanılan Grafik Metot yöntemidir. Bu yöntemde olasılık dağılım fonksiyonunun parametreleri grafik çizilerek bulunur. Bunun için rüzgâr hız verileri düşük rüzgâr hızından yüksek rüzgâr hızına doğru sıralanır. Daha sonra her değer için olasılık değerleri bulunur. Olasılık değerleri bulunduktan sonra kümülatif değer zaman ekseninde çizdirilir. Bu çizim için en yakın doğru parçası elde edilir. Doğru parçasının eğimi şekil parametresini ve bu çizgiden zaman eksenini kestiği nokta ölçek parametresini verir. Bu yöntemi lineer formda yazmak için her iki tarafın logaritması alınır.

$-\left(\frac{v}{c}\right)^{k}=\ln [1-P(v)]$

$k \ln (v)-k \ln (c)=\ln [-\ln [1-P(v)]]$

Burada; $\mathrm{X}=\ln (v), \mathrm{Y}=\ln [-\ln [1-P(v)]]$ değerlerini verir. $\mathrm{A}=k, \mathrm{~B}=-k \ln (c)$ kabul edilirse; $\mathrm{Y}=\mathrm{AX}+\mathrm{B}$ şeklinde lineer denklem bulunur.

Weibull Dağılımında ölçek parametresi ve bu parametre hesaplandıktan sonra rüzgâr enerji santrallerin kurulacağı bölgelerde rüzgâr enerji potansiyelleri hesaplanabilir. Rüzgâr enerji potansiyeli Denklem 6 kullanılarak hesaplanır.

$P_{w}=\frac{1}{2} \rho c^{3} \Gamma\left(1+\frac{3}{k}\right)$

Burada; $P_{w}$ rüzgâr enerji güç yoğunluğu, $\rho$ hava yoğunluğu, $\Gamma$ gama fonksiyonudur. Gama fonksiyonu ise Denklem 7'de verilmiştir.

$\Gamma(x)=\int_{0}^{\infty} e^{-u} u^{x-1} d u$

Kapasite faktörü ise Denklem 8'de verilmiştir.

$C F=\frac{\exp \left[-\left(V_{c} / c\right)^{k}\right]-\exp \left[-\left(V_{r} / c\right)^{k}\right]}{\left(V_{r} / c\right)^{k}-\left(V_{c} / c\right)^{k}}-\exp \left[-\left(V_{f} / c\right)^{k}\right]$

Burada; CF kapasite faktörü, $V_{c}$ rüzgâr türbinin devreye girme rüzgâr hızını, $V_{r}$ rüzgâr türbinin ortalama çalışma rüzgâr hızını, $V_{f}$ rüzgâr türbinin devreden çıkma rüzgâr hızını ifade eder.

\section{3. Örnek Çalışma}

Adilcevaz Bölgesi, Türkiye'nin Doğu Anadolu Bölgesinde bulunan Bitlis iline bağlı bir ilçesidir. Adilcevaz ilçesinin konumu Şekil 2'de gösterilmiştir. Çalışmada Devlet Meteoroloji İl Müdürlüğü'nün 1671 metre rakım, 38.7982 enlem ve 42.7644 boylamda bulunan ölçüm istasyonundaki veriler kullanılmıştır. 


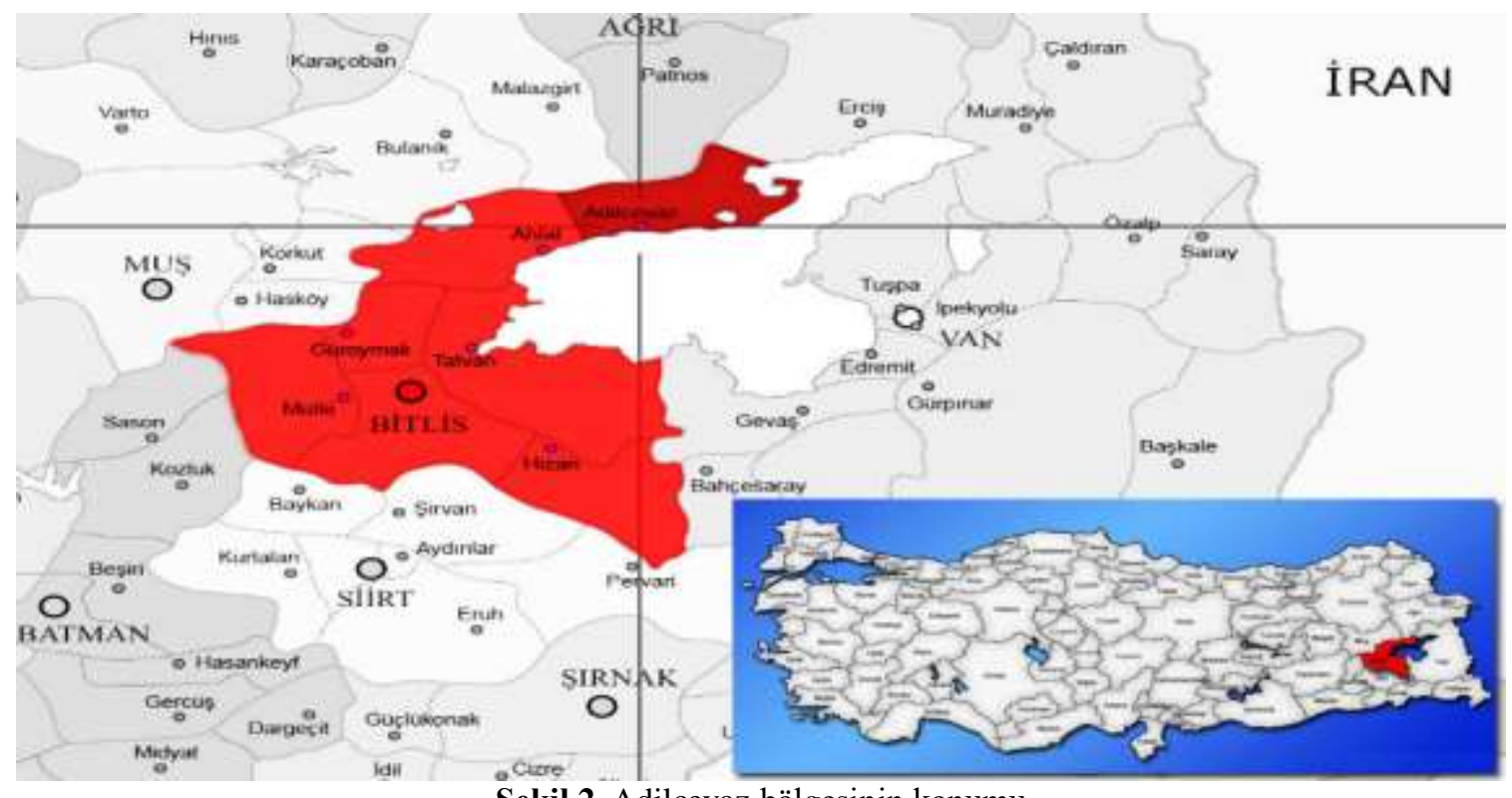

Şekil 2. Adilcevaz bölgesinin konumu

Adilcevaz bölgesi için 2018 yılına ait 10 m yükseklikte ölçülen saatlik rüzgâr hız değerlerinin sınıflandırılması Tablo 3'nin ikinci sütununda rüzgâr hızının ortama değerleri, üçüncü sütunda her bir rüzgâr hızının esme sayısı, dördüncü sütunda olasılık yoğunluğu ve beşinci sütunda kümülatif olasılık yoğunluğu verilmiştir.

Tablo 3. Rüzgâr hız verileri (10 m)

\begin{tabular}{|c|c|c|c|c|}
\hline $\boldsymbol{i}$ & $\boldsymbol{v}_{\boldsymbol{i}}$ & $\boldsymbol{f}_{\boldsymbol{i}}$ & $\boldsymbol{p}_{\boldsymbol{v i}}$ & $\boldsymbol{P}_{\boldsymbol{v i}}$ \\
\hline 0 & 0,5 & 542 & 0,06384 & 0,06384 \\
\hline 1 & 1,5 & 2507 & 0,295289 & 0,359128 \\
\hline 2 & 2,5 & 2838 & 0,334276 & 0,693404 \\
\hline 3 & 3,5 & 1323 & 0,15583 & 0,849234 \\
\hline 4 & 4,5 & 717 & 0,084452 & 0,933687 \\
\hline 5 & 5,5 & 348 & 0,040989 & 0,974676 \\
\hline 6 & 6,5 & 131 & 0,01543 & 0,990106 \\
\hline 7 & 7,5 & 57 & 0,006714 & 0,99682 \\
\hline 8 & 8,5 & 12 & 0,001413 & 0,998233 \\
\hline 9 & 9,5 & 12 & 0,001413 & 0,999647 \\
\hline 10 & 10,5 & 2 & 0,000236 & 0,999882 \\
\hline 11 & 11,5 & 2 & 0,000236 & 1,000118 \\
\hline 12 & 12,5 & 1 & 0,000118 & 1,000236 \\
\hline 13 & 13,5 & 0 & 0 & 1,000236 \\
\hline
\end{tabular}

Tablo 3'deki saatlik rüzgâr hız oranının esme sayı değeri y1l içerisinde 8760 değer olması gerekirken burada 8492 değer mevcuttur. Bunun nedeni 268 farklı saat diliminde rüzgâr hız değerlerinin ölçüm yapan cihaz tarafından ölçülememesidir. Denklem 1'de verilen rüzgâr hız güç denklemi kullanılarak 100 m yükseklik için rüzgâr hız değerlerinin sınıflandırılması ise Tablo 4'de verilmiştir.

Denklem 4 ve Denklem 5 kullanılarak, Tablo 3 ve Tablo 4'den elde edilen X - Y koordinat eksen değerleri ise Tablo 5'de verilmiştir. 
Tablo 4. Rüzgâr Hız Verileri (100 m)

\begin{tabular}{|c|c|c|c|c|}
\hline $\boldsymbol{i}$ & $\boldsymbol{v}_{\boldsymbol{i}}$ & $\boldsymbol{f}_{\boldsymbol{i}}$ & $\boldsymbol{p}_{\boldsymbol{v i}}$ & $\boldsymbol{P}_{\boldsymbol{v i}}$ \\
\hline 0 & 0,5 & 77 & 0,009069 & 0,009069 \\
\hline 1 & 1,5 & 465 & 0,05477 & 0,06384 \\
\hline 2 & 2,5 & 967 & 0,113899 & 0,177739 \\
\hline 3 & 3,5 & 1540 & 0,18139 & 0,359128 \\
\hline 4 & 4,5 & 1675 & 0,197291 & 0,556419 \\
\hline 5 & 5,5 & 1163 & 0,136985 & 0,693404 \\
\hline 6 & 6,5 & 758 & 0,089282 & 0,782686 \\
\hline 7 & 7,5 & 565 & 0,066549 & 0,849234 \\
\hline 8 & 8,5 & 441 & 0,051943 & 0,901178 \\
\hline 9 & 9,5 & 276 & 0,032509 & 0,933687 \\
\hline 10 & 10,5 & 207 & 0,024382 & 0,958068 \\
\hline 11 & 11,5 & 141 & 0,016608 & 0,974676 \\
\hline 12 & 12,5 & 76 & 0,008952 & 0,983628 \\
\hline 13 & 13,5 & 55 & 0,006478 & 0,990106 \\
\hline 14 & 14,5 & 34 & 0,004005 & 0,994111 \\
\hline 15 & 15,5 & 23 & 0,002709 & 0,99682 \\
\hline 16 & 16,5 & 6 & 0,000707 & 0,997527 \\
\hline 17 & 17,5 & 6 & 0,000707 & 0,998233 \\
\hline 18 & 18,5 & 9 & 0,00106 & 0,999293 \\
\hline 19 & 19,5 & 3 & 0,000353 & 0,999647 \\
\hline 20 & 20,5 & 0 & 0 & 0,999647 \\
\hline 25 & 25,5 & 5 & 0,000589 & 1,000236 \\
\hline 26 & 26,5 & 0 & 0 & 1,000236 \\
\hline
\end{tabular}

Tablo 5. Rüzgâr Hız Verilerinin $X$ ve Y Eksen Değerleri a) 10 m b) 100 m

\begin{tabular}{|l|l|}
\hline X Ekseni & Y Ekseni \\
\hline$-0,69315$ & $-2,71858$ \\
\hline 0,405465 & $-0,80985$ \\
\hline 0,916291 & 0,167398 \\
\hline 1,252763 & 0,63765 \\
\hline 1,504077 & 0,998189 \\
\hline 1,704748 & 1,301827 \\
\hline 1,871802 & 1,529491 \\
\hline 2,014903 & 1,74934 \\
\hline 2,140066 & 1,846657 \\
\hline 2,251292 & 2,072924 \\
\hline 2,351375 & 2,202394 \\
\hline
\end{tabular}

a)

\begin{tabular}{|l|l|}
\hline X Ekseni & Y Ekseni \\
\hline$-0,69315$ & $-4,69829$ \\
\hline 0,405465 & $-2,71858$ \\
\hline 0,916291 & $-1,63119$ \\
\hline 1,252763 & $-0,80985$ \\
\hline 1,504077 & $-0,20718$ \\
\hline 1,704748 & 0,167398 \\
\hline 1,871802 & 0,422918 \\
\hline 2,014903 & 0,63765 \\
\hline 2,140066 & 0,839165 \\
\hline 2,251292 & 0,998189 \\
\hline 2,351375 & 1,154272 \\
\hline 2,442347 & 1,301827 \\
\hline 2,525729 & 1,413951 \\
\hline 2,60269 & 1,529491 \\
\hline 2,674149 & 1,636006 \\
\hline 2,74084 & 1,74934 \\
\hline 2,80336 & 1,792113 \\
\hline 2,862201 & 1,846657 \\
\hline 2,917771 & 1,981675 \\
\hline 2,970414 & 2,072924 \\
\hline 3,020425 & 2,072924 \\
\hline
\end{tabular}

b)

Rüzgâr hız verilerinin X - Y Eksen değerleri Matlab ortamında işaretlenip ve bu noktalara uygun bir eğri grafiği 10 m yükseklik için Şekil 3'de ve 100 m yükseklik için Şekil 4'de verilmiştir. 


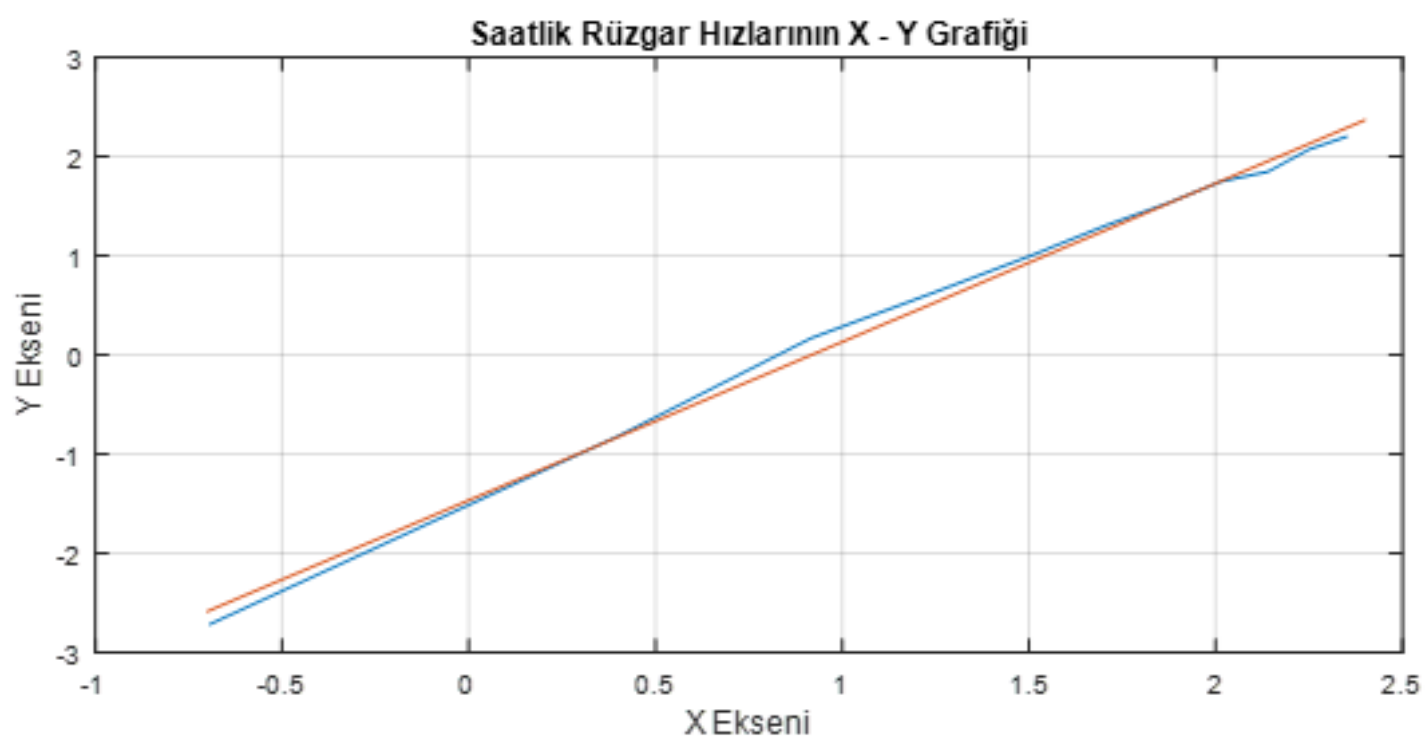

Şekil 3. Rüzgâr hız verilerinin $\mathrm{X}$ ve $\mathrm{Y}$ eksen değerleri $(10 \mathrm{~m})$

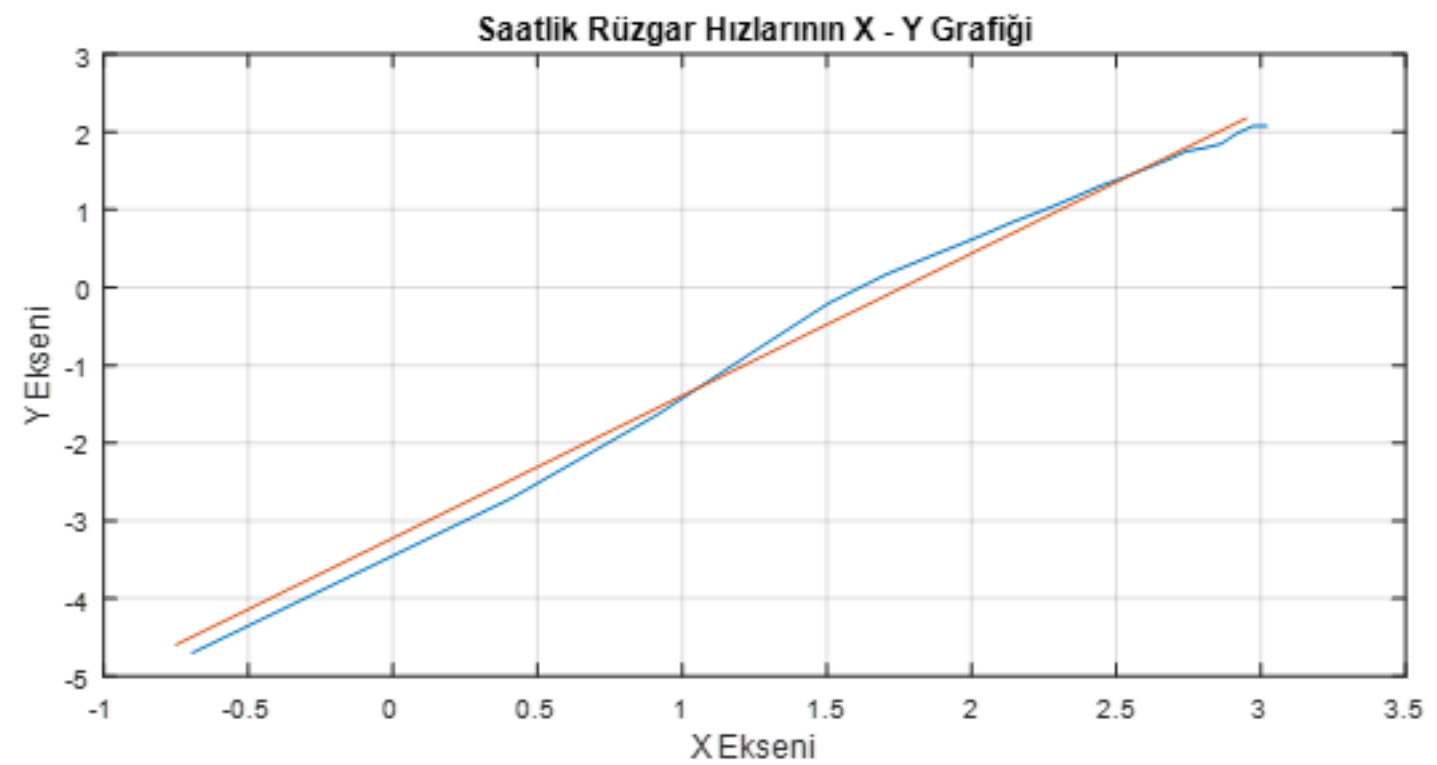

Şekil 4. Rüzgâr hız verilerinin X ve Y eksen değerleri (100 m)

Burada; $10 \mathrm{~m}$ için yapılan hesaplamalarda $\mathrm{y}=1,5567^{*} \mathrm{x}-1,4443$ bulunur. Buradan da $k=$ $1,5567 c=2,5289$ olarak, $100 \mathrm{~m}$ için yapılan hesaplamalarda ise $\mathrm{y}=1,8192 * \mathrm{x}-3,2110$ bulunur. Buradan da $k=1,8192 c=5,8419$ olarak hesaplanmaktadır.

\section{Bulgular}

Bu bölümde Weibull Dağılım sonuçları gerçek rüzgâr hız değerleri ile karşılaştırılmış ve hata analizi yapılmıştır. Bunun yanı sıra etkin rüzgâr yönleri ile saatlik ölçülen rüzgâr hız değerleri verilmiştir. Ölçüm verilerinin alındığ $10 \mathrm{~m}$ yükseklik için gerçek rüzgâr hız değerleri ile hesaplanan ölçek parametresi ve şekil parametresinden elde edilen Weibull Dağ 11 mm grafiği Şekil 5-a)'da verilmiştir. Hellmann Bağıntısı kullanılarak 100 m yükseklik için hesaplanan rüzgâr hız değerleri ile hesaplanan ölçek parametresi ve şekil parametresinden elde edilen Weibull Dağılım grafiği Şekil 5-b)'de verilmiştir. 


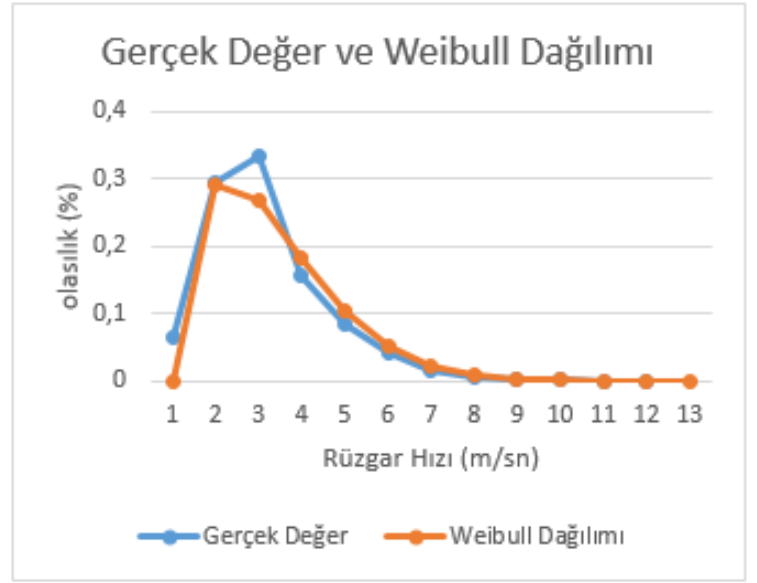

a)

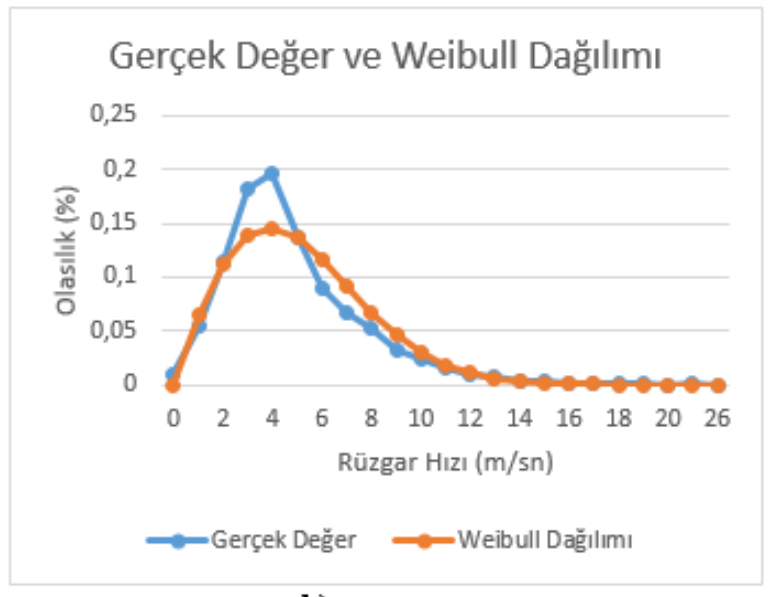

b)

Şekil 5. Gerçek rüzgâr hızı ve Weibull Dağılım Olasılıkları a)10m b)100 m

Yükseklik arttıkça rüzgâr hız değerlerinin olasılık oranları azalmakta fakat ortalama rüzgâr hız değerleri artmaktadır. $\mathrm{Bu}$ durumda rüzgâr enerjisinden dönüştürülecek enerji yoğunluğunu artırmaktadır. Çalışmada incelenen Adilcevaz bölgesi için 2018 yılına ait 10 m yükseklikte ölçülen saatlik rüzgâr hızlarının açı değerleri ise Şekil 6' de verilmiştir.

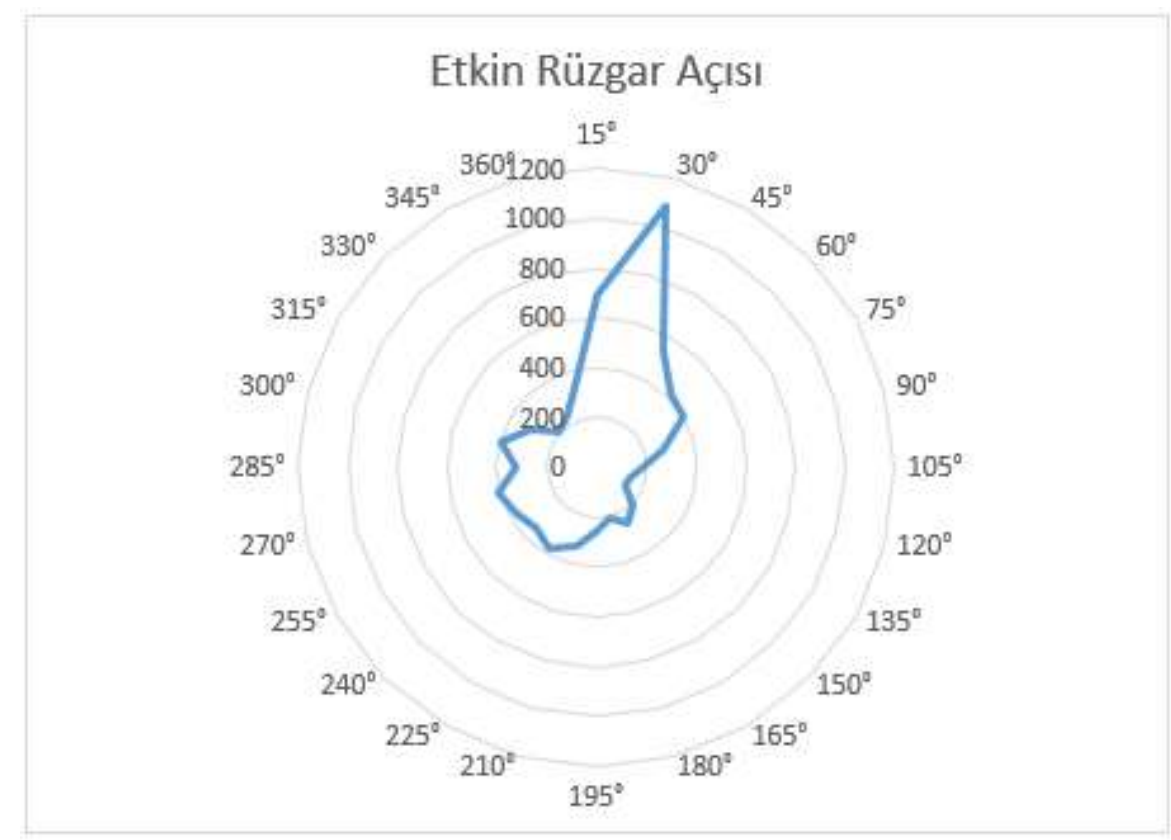

Şekil 6. Rüzgâr hız açısı

Şekil 6 incelendiği zaman etkin rüzgâr açısının yaklaşık $30^{\circ}$ olduğu görülmektedir. Adilcevaz Bölgesinde elde edilen saatlik rüzgâr hız değerleri Şekil 7'de verilmiştir.

Saatlik rüzgâr hız grafiği incelendiğinde ortalama rüzgâr hızının en yüksek olduğu aylar ilkbahar ayları, sonra sırasıyla kış ayları ve sonbahar ayları gelmektedir. Rüzgâr hızının en düşük olduğu aylar ise yaz ayları olduğu görülmektedir. Weibull Dağılımı ile elde edilen sonuçların hata analizleri yapıldı ̆̆ında elde edilen sonuçlar Tablo 6'da verilmiştir. 


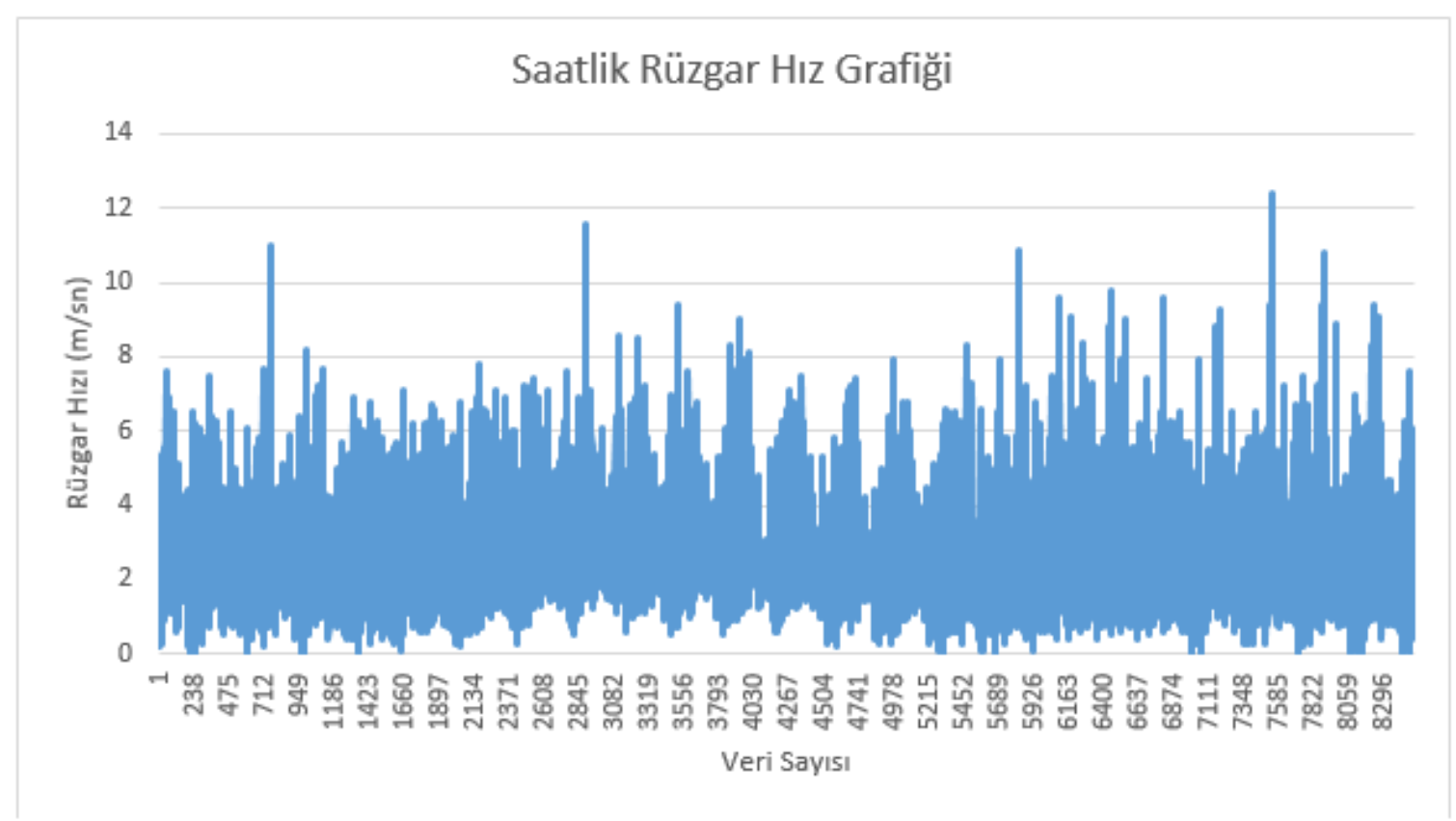

Şekil 7. Saatlik rüzgâr hızları

Tablo 6. Weibull Dağılım değerleri ve hata oranları a)10 m b)100 m

\begin{tabular}{|l|l|}
\hline Weibull Dağlımı & Hata (\%) \\
\hline 0,290071 & 0,017438 \\
\hline 0,269859 & 0,192514 \\
\hline 0,183644 & $-0,17876$ \\
\hline 0,103145 & $-0,22162$ \\
\hline 0,050018 & $-0,22055$ \\
\hline 0,021446 & $-0,3902$ \\
\hline 0,008252 & $-0,22939$ \\
\hline 0,002879 & $-1,03751$ \\
\hline 0,000918 & 0,35038 \\
\hline 0,000269 & $-0,14241$ \\
\hline $7,28 \mathrm{E}-05$ & 0,690693 \\
\hline $1,83 \mathrm{E}-05$ & 0,844655 \\
\hline
\end{tabular}

a)

\begin{tabular}{|l|l|}
\hline Weibull Dağlımı & Hata (\%) \\
\hline 0,070446 & $-0,28651$ \\
\hline 0,112249 & 0,014255 \\
\hline 0,133976 & 0,261218 \\
\hline 0,138208 & 0,299307 \\
\hline 0,129046 & 0,057731 \\
\hline 0,111407 & $-0,24812$ \\
\hline 0,089987 & $-0,35251$ \\
\hline 0,068508 & $-0,31922$ \\
\hline 0,049407 & $-0,52015$ \\
\hline 0,033874 & $-0,38965$ \\
\hline 0,022139 & $-0,33336$ \\
\hline 0,013822 & $-0,54446$ \\
\hline 0,008258 & $-0,27503$ \\
\hline 0,004728 & $-0,18078$ \\
\hline 0,002597 & 0,041321 \\
\hline 0,00137 & $-0,93832$ \\
\hline 0,000694 & 0,017349 \\
\hline 0,000339 & 0,680541 \\
\hline 0,000159 & 0,550149 \\
\hline $7,18 \mathrm{E}-05$ & hata \\
\hline $7,86 \mathrm{E}-07$ & 0,998665 \\
\hline $2,87 \mathrm{E}-07$ & hata \\
\hline
\end{tabular}

b)

Weibull Dağılım ile gerçek rüzgâr hız değerleri arasındaki hata oranları incelendiğinde $10 \mathrm{~m}$ yükseklikte hesaplanan hata oranları \% 1,03'ü geçmemektedir. $100 \mathrm{~m}$ yükseklikteki hata oranları ise \% 1'den az olduğu Tablo 6'de görülmektedir.

Denklem 7 kullanılarak rüzgâr enerji güç yoğunluğu $10 \mathrm{~m}$ yükseklik için hesaplanırsa; $P_{w}=$ $25,4520 \mathrm{~W} / \mathrm{m}^{2}$ olarak bulunur. $100 \mathrm{~m}$ yükseklik için rüzgâr enerji güç yoğunluğu hesaplanırsa; $P_{w}=$ $299,0315 \mathrm{~W} / \mathrm{m}^{2}$ olarak bulunur. Aynı şekilde yapılan hesaplamalarda kapasite faktörü $10 \mathrm{~m}$ yükseklik için $\mathrm{CF}=0,027$ olarak $100 \mathrm{~m}$ yükseklik için $\mathrm{CF}=0,210$ olarak hesaplanır. 


\section{Sonuç}

Rüzgâr ölçüm istasyonunda ölçülen rüzgâr hız ve yön verileri, rüzgâr enerji santralleri projelerinin uygulanabilmesi açısından önem arz etmektedir. Yapılan bu çalışmada Adilcevaz bölgesi için 2018 yılına ait veriler kullanılmıştır. Bunun sonucunda; $100 \mathrm{~m}$ için Weibull Dağılımı ile gerçek veriler arasındaki hata oranı $10 \mathrm{~m}$ yükseklikteki hata oranından daha düşük olduğu ve enerji potansiyel değeri 100 m yükseklik için $P_{w}=299,0315 \mathrm{~W} / \mathrm{m}^{2}$ ve kapasite faktörü $\mathrm{CF}=0,210$ olarak hesaplanmıştır. Ayrıca $10 \mathrm{~m}$ yükseklik için ortalama hata değeri 0,3763 ve standart sapma değeri 0,5021 olarak, $100 \mathrm{~m}$ yükseklik için ortalama hata değeri 0,33210 ve standart sapma değeri 0,3942 olarak bulunmuştur. Bu ölçülen değerler referansında hesaplanan enerji potansiyel verileri değerlendirilebilir düzeyde olduğu görülmektedir.

Bu çalışmada Adilcevaz bölgesi için rüzgâr enerji potansiyelini belirlemek amacıyla yapılan bir ön çalışma niteliğindedir. Bölgede bir rüzgâr enerji santrali kurmak için daha detaylı çalışmalar ve daha uzun süreli rüzgâr verileri kullanılmalıdır. Ülkemizde yenilenebilir enerji kaynaklarının kullanımını artıracak bu tür çalışmaların artırılması, artan enerji talebini karşılamak ve enerjide dışa olan bağımlılığı büyük oranda azaltacaktır.

\section{Yazarların Katkısı}

Çalışmada tüm yazarlar eşit oranda katkı sunmuştur.

\section{Çıkar Çatışması Beyanı}

Yazarlar arasında herhangi bir çıkar çatışması bulunmamaktadır.

\section{Araştırma ve Yayın Etiği Beyanı}

Yapılan çalışmada, araştırma ve yayın etiğine uyulmuştur.

\section{Kaynaklar}

[1] Kaplan Y.A. 2016. Rayleigh ve Weibull Dağılımları Kullanılarak Osmaniye Bölgesinde Rüzgar Enerjisinin Değerlendirilmesi. Süleyman Demirel Üniversitesi Fen Bilimleri Enstitüsü Dergisi, 20 (1): 62-71.

[2] Gülersoy T., Çetin, N.S. 2010. Menemen Bölgesinde Rüzgar Türbinleri İçin Rayleigh ve Weibull Dağılımlarının Kullanılması. Politeknik Dergisi, 13 (3): 209-213.

[3] Yıldırım U., Gazibey Y., Güngör A. 2012. Niğde İli Rüzgar Enerjisi Potansiyeli. Niğde Üniversitesi Mühendislik Bilimleri Dergisi, 1 (2): 37-47.

[4] Kurban M., Kantar Y.M., Hocaoğlu F.O. 2007. Weibull Dağılımı Kullanılarak Rüzgar Hız ve Güç Yoğunluklarının İstatiksel Analizi. Afyon Kocatepe Üniversitesi Fen Bilimleri Dergisi, 7 (2): 205-218.

[5] Lublertlop K., Jeeng Min L., 2015. Economic Analysis of Wind Turbine Installation in Taiwan, Hindawi Publising Corporation, Mathematical Problems in Engineering. Macroscopic/Mesoscopic Computational Materials Science Modeling and Engineering, 2015: Article ID 614541.

[6] Wang L., Chanan S., 2006. Tradeoff Between Risk and Cost in Economic Dispatch Including Wind Power Penetration Using Particle Swarm Optimization. International Conference on Power Technology, Chongqing, 7-12.

[7] Bilal B.O., Cheikh K., Vincent S., Papa A., Mamoudou N., 2014. Economic Analysis of Wind Electricity Generation in the Northern Coast of Senegal. International Journal of Metrology and Quality Engineering, 5 (3).

[8] Celik A.N. 2007. A Techno-Economic Analysis of Wind Energy in Southern Turkey. International Journal of Green Energy, 1233-1247.

[9] Blanco M.I. 2009. The Economics of Wind Energy. Renewable and Sustainable Energy Reviews, 13. $1372-1382$. 
[10] Kestane Ö., Ülgen K. 2017. Techno-Economic Analysis of Wind Power Plants: A Case Study of Milas-Turkey. Energy Soruces, Part B: Economics, Planning and Policy, 1088-1100.

[11] Arslan O. 2010. Technoeconomic Analysis of Electricity Generation From Wind Energy in Kutahya, Turkey. Energy, 120-131.

[12] Gökçek M., Genç M.S. 2009. Evaluation of Electrcity Generation and Energy Cost of Wind Energy Conversion Systems (WECSs) in Central Turkey. Applied Energy, 86: 2731-2739.

[13] Taner T. 2018. Economic Analysis of a Wind Power Plant: A Case Study for the Cappadocia Region. Journal of Mechanical Science and Technology, 32: 1379-1389.

[14] Taner T. 2014. Energy and Economic Analysis of the Wind Turbine Plant's Draft for the Aksaray City. Applied Ecology and Environmental Sciences, 82-85.

[15] https://www.epdk.org.tr/ (Erişim Tarihi: 31.07.2019). 